\title{
Serum myoglobin and creatine kinase enzymes in acute myocardial infarction treated with Anistreplase
}

\author{
D A McCullough, P G Harrison, J M Forshall, J B Irving, R J Hillman
}

\begin{abstract}
Aims: To compare plasma myoglobin concentration and cardiac enzyme activity with electrocardiographic (ECG) changes in two groups of patients (reperfused and non-reperfused) participating in a placebo-controlled randomised double blind trial of treatment of myocardial infarction (MI) with intravenous thrombolytic therapy (Anistreplase).

Methods: Twenty two patients with confirmed MI obeying strict inclusion and exclusion criteria were studied.

Plasma myoglobin was measured by radioimmunoassay and creatine kinase enzyme (CK and CKMB) by NAC activated and NAC activated/immunoinhibition methods respectively in all patients before and at frequent intervals after injection of Anistreplase or placebo. Patients were divided into reperfused (R) and non-reperfused (NR) groups on the basis of ECG criteria. Reperfusion was diagnosed if the measured ST segment elevation fell by $\geqslant 50 \%$ at 2 hours post dosing.
\end{abstract}

Results: The time to peak (TTP) myoglobin was significantly less in the $R$ group compared with the NR group but there was considerable overlap in the range of values.

The area under the enzyme time curves (AUCs) and summed ST segment $\Sigma$ ST elevations were significantly smaller in the $R$ compared with the NR group.

Conclusions: Although TTP myoglobin results were significantly lower in the $R$ group, TTP myoglobin will probably not be useful as an non-invasive indicator of reperfusion because of the overlap in values between the two groups. The significant reduction in the AUC and $\Sigma S T$ only in the $R$ group suggests decreased infarct size. However, in this small preliminary study reperfusion did not occur more frequently with Anistreplase than without.

P-anisoylated (human) Lys-plasminogenstreptokinase activator complex (APSAC or Anistreplase) is a novel thrombolytic agent introduced for use in the early treatment of myocardial infarction (MI). ${ }^{1}$ Reperfusion of thrombosed coronary arteries following treatment with thrombolytic agents results in a rapid release of myoglobin, the cardiac enzyme creatine kinase (CK) and its isoenzyme (CKMB) into the circulation.

Recent studies have shown that myoglobin release occurs earlier than that of $\mathrm{CK}$ or CKMB following reperfusion after $\mathrm{MI}^{2}$ A reduced time from dosing to peak (TTP) has been suggested as an indicator of reperfusion after $\mathrm{MI} .^{3} \mathrm{~A}$ fall in the maximum elevated ST segment of $\geqslant 50 \%$ has been shown to be a valid index of reperfusion. ${ }^{4}$

The aim of the study was to compare plasma myoglobin concentration and cardiac enzyme activity with ECG changes in two groups of patients (reperfused and non-reperfused) participating in a placebo-controlled randomised double-blind trial of intravenous Anistreplase. Myoglobin release would potentially be a simple non-invasive method of detecting reperfusion and re-infarction (especially when ECG changes were equivocal) suitable for hospitals without facilities for angiography.

Failure to reperfuse is associated with a higher risk of in-hospital and long term mortality. Acute percutaneous transluminal coronary angioplasty can achieve recanalisation in most of these patients if they are identified early. ${ }^{5}$ The amount of CK and CKMB released as estimated from the area under the enzyme time curve (AUC) is considered by many authors to be proportional to infarct size in the absence or presence of thrombolytic therapy. Since the 12 lead ECG summed ST segment elevation ( $\Sigma$ ST) has also been shown to be proportional to infarct $\operatorname{size}^{78}$ then this study should also confirm if early reperfusion reduces infarct size. ${ }^{9}$

\section{Methods}

Twenty two patients (17 males, five females) obeying strict inclusion criteria were admitted to the study and randomised to receive either Anistreplase or placebo. ${ }^{10}$

Informed consent was obtained from all patients. Blood samples were taken for myoglobin, CK, and CKMB: (1) before dosing with Anistreplase or placebo, (2) at 15 minute intervals post dosing for the first 4 hours, (3) hourly for the next 4 hours, (4) at 10,12,18, and 24 hours, and (5) 12 hourly for up to 72 hours.

Patients were categorised into either reperfused (R) or non-reperfused (NR) groups on the basis of ECG criteria. Twelve lead ECGs were carried out on a Hewlett-Packard 4700A electrocardiograph. ST elevation was measured at the $\mathrm{J}$ point in the lead showing maximum ST shift on admission. ECGs were 
Table 1 Non-significant patient characteristics in the reperfused groups (mean and range)

\begin{tabular}{|c|c|c|c|c|c|c|}
\hline \multirow{2}{*}{$\begin{array}{l}\text { Patient } \\
\text { group }\end{array}$} & \multirow{2}{*}{$\begin{array}{l}\text { Age } \\
\text { (years) }\end{array}$} & \multirow{2}{*}{$\begin{array}{l}\text { Height } \\
(\mathrm{cm})\end{array}$} & \multirow{2}{*}{$\begin{array}{l}\text { Weight } \\
(\mathrm{kg})\end{array}$} & \multicolumn{2}{|c|}{$\begin{array}{l}\text { Infarction site } \\
\text { (male :female ratio) }\end{array}$} & \multirow{2}{*}{$\begin{array}{l}\text { Time from } \\
\text { outset of } \\
\text { symptoms } \\
\text { to dosing }(h)\end{array}$} \\
\hline & & & & Anterior & Inferior & \\
\hline $\begin{array}{l}\text { Reperfused } \\
(\mathrm{n}=9) \\
\text { Non-reperfused } \\
(\mathbf{n = 8 )}\end{array}$ & $\begin{array}{l}56 \cdot 7 \\
(50-69) \\
58 \\
(44-67)\end{array}$ & $\begin{array}{l}163 \cdot 0 \\
(157-165) \\
168 \cdot 5 \\
(163-174)\end{array}$ & $\begin{array}{c}70 \cdot 6 \\
(57-91) \\
68 \cdot 5 \\
(52-81)\end{array}$ & $\begin{array}{c}4 \\
(3: 1) \\
2 \\
(2: 0)\end{array}$ & $\begin{array}{c}5 \\
(4: 1) \\
6 \\
(5: 1)\end{array}$ & $\begin{array}{l}3 \cdot 64 \\
(2-5) \\
3 \cdot 55 \\
(2 \cdot 5-4 \cdot 75)\end{array}$ \\
\hline
\end{tabular}

Table 2 Time to peak from dosing with Anistreplase or placebo for myoglobin, $C K$, and $C K M B$ and $A U C$ for $C K$ and $C K M B$ (means and ranges)

\begin{tabular}{|c|c|c|c|c|c|}
\hline \multirow{2}{*}{$\begin{array}{l}\text { Patient } \\
\text { group }\end{array}$} & \multicolumn{3}{|c|}{ Time to peak from dosing $(h)$} & \multicolumn{2}{|c|}{$\begin{array}{l}\text { AUC } \\
\text { (IU/l per hour })\end{array}$} \\
\hline & Myoglobin & $C K$ & $C K M B$ & $C K$ & $C K M B$ \\
\hline $\begin{array}{l}\text { Reperfused } \\
(\mathrm{n}=9) \\
\text { Non-reperfused } \\
(\mathrm{n}=8) \\
\text { P reperfused } v \text { non-reperfused }\end{array}$ & $\begin{array}{l}2 \cdot 31 \\
(1-3 \cdot 5) \\
5 \cdot 3 \\
(2 \cdot 75-8) \\
<0 \cdot 01\end{array}$ & $\begin{array}{l}13 \cdot 6 \\
(5-24) \\
19 \\
(8-24) \\
\text { NS }\end{array}$ & $\begin{array}{l}11 \\
(4-18) \\
14 \\
(8-24) \\
\text { NS }\end{array}$ & $\begin{array}{l}2963 \\
(481-7305) \\
5954 \\
(1789-10804) \\
<0.01\end{array}$ & $\begin{array}{l}238 \\
(84-771) \\
519 \\
(204-844) \\
<0.05\end{array}$ \\
\hline
\end{tabular}

NS $=$ not statistically significant, $p>0.05$.

independently reported by two observers (JBI and $\mathrm{RJH}$ ).

Successful reperfusion was considered to have occurred if the ST segment elevation (measured at the $\mathrm{J}$ point) fell by $\geqslant 50 \%$ at 2 hours post dosing. The size of the infarction prior to dosing was estimated from the $\Sigma S T$ elevation on the 12-lead electrocardiograph. The AUC were calculated from the geometry of the graphs.

Myoglobin was measured by a radioimmunoassay technique (Nuclear Medical System Pharmaceuticals Inc, Newport Beach, California.) CK activity was measured by an NAC-activated kit and CKMB using an NACactivated immunoinhibition kit (Boehringer Mannheim) at $37^{\circ} \mathrm{C}$.

\section{Statistics}

Results are expressed as mean (range) unless otherwise stated. Non-parametric group comparisons were made using the Wilcoxon rank

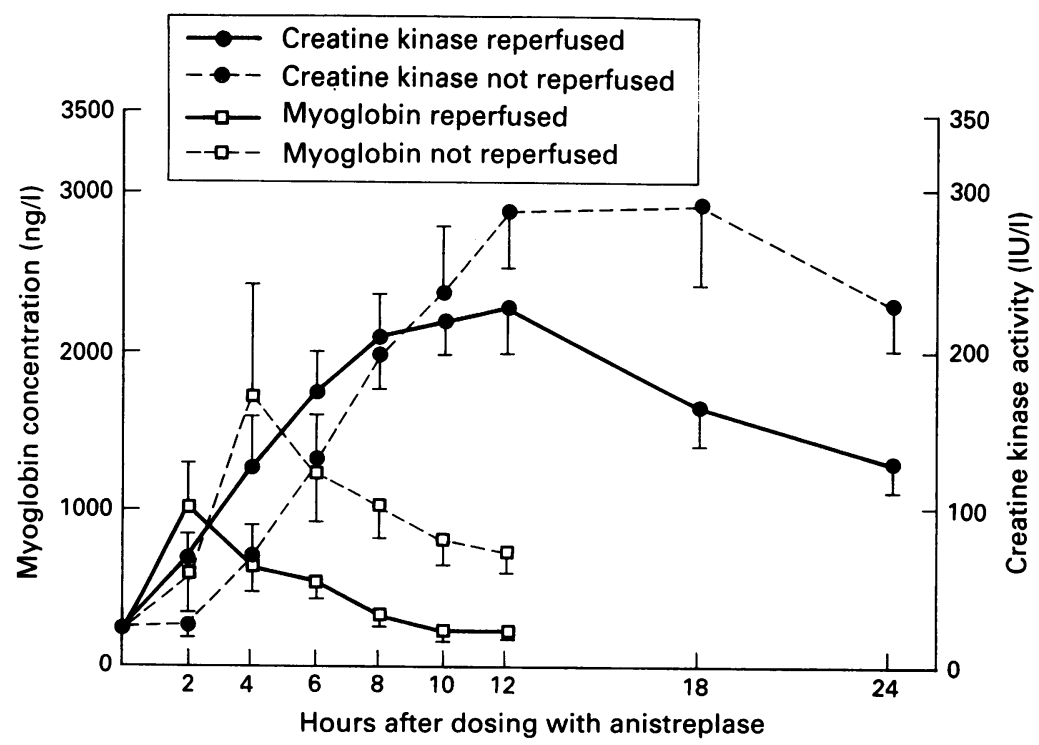

Serum myoglobin and creatine kinase isoenzymes (CKMB) after dosing with Anistreplase (or placebo) in reperfused and non-reperfused groups. (Mean with standard error of the mean.) sum test. Correlations were performed using standard statistical methods. Significance was established at the level of $\mathrm{p}<0.05$.

\section{Results}

Equivocal ECG results were obtained in five patients because of either left ventricular hypertrophy or old myocardial infarction and they are considered separately later.

Of the 17 patients remaining nine showed reperfusion (R) and eight did not (NR) on the basis of changes in the maximum ST segment elevation pre-dosing compared with 2 hours post dosing. Thus the $\mathbf{R}$ group showed a significant decrease in maximum ST segment elevation from $3 \cdot 6(2-8)$ pre-dosing to $1 \cdot 1(0-4)$ $\mathrm{mm}$ post dosing $(69 \% ; \mathrm{p}<0.01)$, whereas comparable changes for the NR group were an increase from $2.9(2-5)$ to $4 \cdot 1$ (1-7) $\mathrm{mm}(44 \%$; $\mathrm{p}<0.05)$.

Age, height, weight, infarction site (anterior: inferior ratio), male:female ratio, and time from outset of symptoms to dosing were comparable in the two groups (table 1).

Although the TTP myoglobin concentation was significantly less in the $\mathbf{R}$ compared with the NR group, there was considerable overlap in the range of values. The TTP, CK and CKMB were not significantly different in the two groups (figure, table 2). The areas under the CK and CKMB enzyme time curves were significantly smaller in the $R$ compared with the NR group (table 2).

Prior to dosing the $\Sigma$ ST elevation was not significantly different in the two groups. In the $\mathbf{R}$ group the $\Sigma S T$ elevation decreased significantly from 11.2 (range 4-28.5) pre-dosing to 3.8 (range $0-17$ ) $\mathrm{mm}$ at 2 hours post dosing whereas it increased non-significantly from 7.6 $(4 \cdot 5-17)$ to $11(2 \cdot 5-23 \cdot 5)$ in the NR group in this period (table 3 ).

On pooling the results ( $R$ and NR) there was a significant positive correlation between TTP myoglobin with the AUC for CK ( $r=0.60$; $p<0.01)$ as well as with the AUC for CKMB $(r=0.61: p<0.01)$. There was also a significant positive correlation between $\Sigma$ ST at 2 hours post dosing with AUC for CKMB ( $\mathbf{r}=$ 
Table 3 Summed ST segment changes in 12-lead ECG pre-dosing $(\Sigma S T)_{0}$ and 2 hours post-dosing $(\Sigma S T)_{2}$ with Anistreplase or placebo in reperfused $(R)$ and non-reperfused (NR) groups (mean and range)

\begin{tabular}{lllll}
\hline $\begin{array}{l}\text { Patient } \\
\text { group }\end{array}$ & $\begin{array}{l}\Sigma S T_{0} \\
(\mathrm{~mm})\end{array}$ & $\begin{array}{c}\Sigma S T_{2} \\
(\mathrm{~mm})\end{array}$ & $\begin{array}{l}\text { Change } \\
\Sigma S T(\%)\end{array}$ & $\begin{array}{l}P \\
\Sigma S T_{1} v \Sigma S T_{2}\end{array}$ \\
\hline$R$ & $11 \cdot 2$ & $3 \cdot 8$ & $-7 \cdot 4(66)$ & 0.01 \\
NR & $(4-28 \cdot 5)$ & $(0-17)$ & $(-1.5-16 \cdot 5)$ & NS \\
P R $v$ NR & $7 \cdot 6$ & $11.4(45)$ & \\
\hline
\end{tabular}

NS $=$ not statistically significant, $p=0.05$.

$0.74 ; \mathrm{p}<0.001)$ as well as with the AUC for CK $(r=0.69 ; p<0.01)$.

When the drug code became available it was revealed that of the nine patients who showed reperfusion, four had received Anistreplase and five placebo, whereas of the eight patients in the NR group, four had received Anistreplase and four placebo. In the group of patients with equivocal ECG findings the biochemical results would have suggested reperfusion in three patients and non-reperfusion in two, on the basis of shorter TTP myoglobin $(2 \cdot 75,3 \cdot 25$ and $7 \cdot 5 \mathrm{~h}$ ) and lower AUC CKMB (136, 158 and $282 \mathrm{IU} / 1$ per hour) in the former compared with the latter group (5 and 8 hours) and (934 and $1000 \mathrm{IU} / 1$ per hour) respectively.

Of the three where the biochemical findings indicated reperfusion, two had received Anistreplase and one had placebo, whereas of the two whose results did not indicate reperfusion one had Anistreplase and one had placebo.

\section{Discussion}

The comparability of the $\Sigma$ ST elevations in the $R$ and NR groups suggests that the infarct sizes were similar prior to dosing. ${ }^{78}$ Therefore, any differences in biochemical parameters (myoglobin, enzymes) between the two groups after treatment are unlikely to be due to inequality in infarct size prior to dosing.

The TTP myoglobin concentration was significantly less in the $\mathbf{R}$ group compared with the NR group. However, serum myoglobin measurement will probably not be useful as a non-invasive indicator of reperfusion because of the overlap in the ranges of TTP values between the R and NR groups. Therefore, it may not be possible for individual patients to be categorised.

No significant difference was found between the two groups in the TTP for either CK or CKMB. A reduced TTP after treatment with Anistreplase (compared with placebo) has been reported for $\mathrm{CK} .^{911}$

Many recent studies have demonstrated that the AUC for CK or CKMB is a valid index of the size of the myocardial infarction. ${ }^{611} 12$ As the AUC for CK and CKMB is significantly less in the $\mathbf{R}$ compared with the NR group, this suggests reduction in the size of the infarct in the former group. The significant positive correlation between TTP for myoglobin and
AUC for CK and CKMB suggests that a shorter TTP myoglobin is associated with a decreased AUC and infarct size. Since the TTP for myoglobin in the $\mathbf{R}$ group is significantly less than the NR group this indicates that early reperfusion (resulting in a shorter TTP myoglobin) leads to a decreased AUC and size of infarct.

The $\Sigma$ ST elevation is also considered to be an index of infarct size. ${ }^{78}$ The $\Sigma S T$ fell significantly (from pre-dosing values) at 2 hours post-dosing only in the $R$ group, indicating a decreased infarct size in the $R$ but not the NR group. However, since the number of patients receiving Anistreplase in the $R$ and NR groups was equal (four) then the differing effects on TTP myoglobin, AUC, and infarct size in the two groups are unlikely to be due solely to the drug. The results of this preliminary study do not therefore explain the recent report of a significant $(47 \%)$ reduction in 30 day mortality in double blind trials with Anistreplase. ${ }^{10}$

1 Ikram S, Lewis S, Bucknall C, et al. Treatment of acute myocardial infarction with anisoylated plasminogen strepmyocardial infarction with anisoylated plasminogen strep-

2 MacLennan BA, McMaster A, Webb SW, et al. High dose intravenous streptokinase in acute myocardial infarction-short and long term prognosis. Br Heart J 1986; 55:231-9.

3 Ellis AK, Little T, Masud ARZ, Klocke PJ. Patterns of myoglobin release after reperfusion of injured myocardium. Circulation 1985;72:639-47.

4 Hogg KJ, Hornung RS, Fowler CA, et al. Electrocardiographic prediction of coronary artery patterns after thrombolytic treatment in acute myocardial infarction: use of the ST segment as a non-invasive marker. Br Heart $J$ 1988; 60:275-80.

5 Califf RM, O'Neill W, Stack RS, et al. Failure of simple clinical measurements to predict perfusion status after intravenous thrombolysis. Ann Intern Med 1988;108: intraven

6 De Zwann C, Willems GM, Vermeer R, et al. Enzyme tests in the evaluation of thrombolysis in acute myocardial infarction. Br Heart $J 1988 ; 59: 175-83$.

7 Hugenholtz PG, Simoons ML, Lubsen J, Vermeer F. Choice of strategy for reperfusion in acute myocardial infarction. Triangle 1987;26:73-89.

8 Anderson JL, Marshall HW, Bray BE, et al. A randomised trial of intracoronary streptokinase in the treatment of acute myocardial infarction. N Engl J Med 1983;308: 1312-8.

9 Hackworthy RA, Sorensen SG, Fitzpatrick PG, et al. Effect of reperfusion on electrocardiographic and enzymatic of reperfusion infarct size: result of a randomised multicenter study of intravenous anisoylated plasminogen streptokinase complex (APSAC) versus intracoronary streptokinase in acu myocardial infarction. Am Heart $J$ 1988;116:903-14.

10 Aims Study Group. Effect of intravenous APSAC on mortality after acute myocardial infarction. Preliminary report of a placebo controlled clinical trial. Lancet 1988; i:872-4.

11 Been M, De Bono DP, Muir AL, et al. Coronary thrombolysis with intravenous anisoylated plasminogen streptokinase complex BRL 26921. Br Heart J 1985;53:253-9.

12 Hackel DB, Reimer KA, Ideker RE, et al. Comparison of enzymatic and anatomic estimates of myocardial infarct size in man. Circulation 1984;5:824-35. 